\title{
Coil Occlusion of a Femoral Arteriovenous Fistula
}

\author{
Kevin O'D. Maher, MD, and Thomas R. Lloyd, ${ }^{*}$ MD, FSCAI \\ A femoral arteriovenous fistula was discovered in a 17-mo-old child with congenital heart \\ disease and prior femoral cardiac catheterization. The fistulous connection was clearly \\ visible by angiography with vein compression, and the fistula was closed percutaneously \\ using a Gianturco coil. Cathet. Cardiovasc. Intervent. 51:308-311, 2000. \\ (1) 2000 Wiley-Liss, Inc.
}

Key words: cardiac catheterization; embolization; angiography

\section{INTRODUCTION}

Femoral arteriovenous fistula (FAVF) is an uncommon but significant complication of cardiac catheterization from the femoral route [1]. We report successful transcatheter coil occlusion of a large FAVF in a 17-moold patient with functionally a single ventricle.

\section{CASE REPORT}

A 17-mo-old, 9.9-kg child with an unbalanced atrioventricular septal defect, hypoplastic left ventricle, D-transposition of the great arteries, and pulmonary atresia was seen for elective cardiac catheterization to determine his suitability for a Fontan procedure. A modified Blalock-Taussig shunt had been performed when the infant was 5 days old, followed 8 mo later by a hemi-Fontan procedure. The patient was growing well and was mildly cyanotic with systemic arterial oxygen saturation of $88 \%$. There were no other cardiovascular symptoms, including claudication or lower-extremity edema. On physical examination, a continuous bruit and prominent thrill were present in the right groin. The family and other medical care providers had not recognized the thrill previously. Diagnostic cardiac catheterization had been performed through the right femoral artery and vein when the infant was age $5 \mathrm{mo}$, before a hemi-Fontan procedure. No complications of catheterization had been noted, and the postoperative course was uneventful.

Owing to the presumptive diagnosis of FAVF, catheterization was undertaken through the left femoral artery and vein as well as the right subclavian vein. Oximetry and angiography showed significant left-to-right shunting at the FAVF. Oxygen saturation levels were $63 \%$ in the superior vena cava, $77 \%$ in the inferior vena cava, $88 \%$ in the aorta, and $93 \%$ in the left atrium. Right ventricular volume overload was present, with a right ventricular end-diastolic volume index of $182 \mathrm{~mL} / \mathrm{m}^{2}$. The patient was otherwise a good Fontan candidate.
A 4F Judkins left coronary artery catheter with a 2.5-cm curve (Mallincrodt Medical, St. Louis, MO) was advanced from the left femoral artery to the aortic bifurcation. The tip of a 0.035 -inch J-tipped guide wire (Argon Inc., Athens, Texas) was advanced through the catheter and directed at the right iliac artery. The coronary catheter was advanced over the wire until its tip engaged the mouth of the iliac artery. At this point the guide wire and then the catheter were advanced easily into the right femoral artery. Angiography showed FAVF with rapid runoff. Dense opacification of both femoral artery and vein substantially obscured the fistula itself. The Judkins left coronary artery catheter was exchanged for a $4 \mathrm{~F}$ Judkins right coronary artery catheter to catheterize the FAVF selectively. Catheter entry into the FAVF was facilitated by placement of a metal clamp over the inguinal thrill for use as a fluoroscopic landmark, and with the aid of a 0.035-inch Glide wire (Medi-tech, Watertown, MA), the catheter was advanced through the FAVF into the right femoral vein. Injection of radiographic contrast into the right femoral vein during manual compression of the vein superior to the catheter tip resulted in retrograde filling of the fistula tract, clearly showing the size and course of the fistulous connection (Fig. 1).

A single Gianturco coil (occluding spring embolus; Cook, Bloomington, IN) of 0.035 -inch caliber, $4 \mathrm{~cm}$ in length, and a 3-mm helical diameter was chosen for occlusion of the FAVF. The coil delivery technique was similar to the technique used for coil embolization of the ductus arteriosus [2]. A single coil loop was placed on the venous

University of Michigan Congenital Heart Center, C. S. Mott Children's Hospital, University of Michigan, Ann Arbor, Michigan

*Correspondence to: Dr. Thomas Lloyd, F 1310 MCHC, Box 0204, 1500 E. Medical Center Drive Ann Arbor, MI 48109-0204.

E-mail: 1loydt@umich.edu

Received 23 February 2000; Revision accepted 25 April 2000 
Fig. 1. A femoral arteriovenous fistula is evident on angiography of the right femoral vein, the catheter from the contralateral femoral artery having passed through the fistula. The femoral vein is compressed externally during injection by the angiographer's finger, promoting retrograde filling of the fistula. The fistula (arrow) is approximately $4 \mathrm{~mm}$ long with diameters ranging from 1.7 to $3.0 \mathrm{~mm}$. Note the hemostat positioned on the drapes with its tip pointing to the site of maximum thrill in the groin.

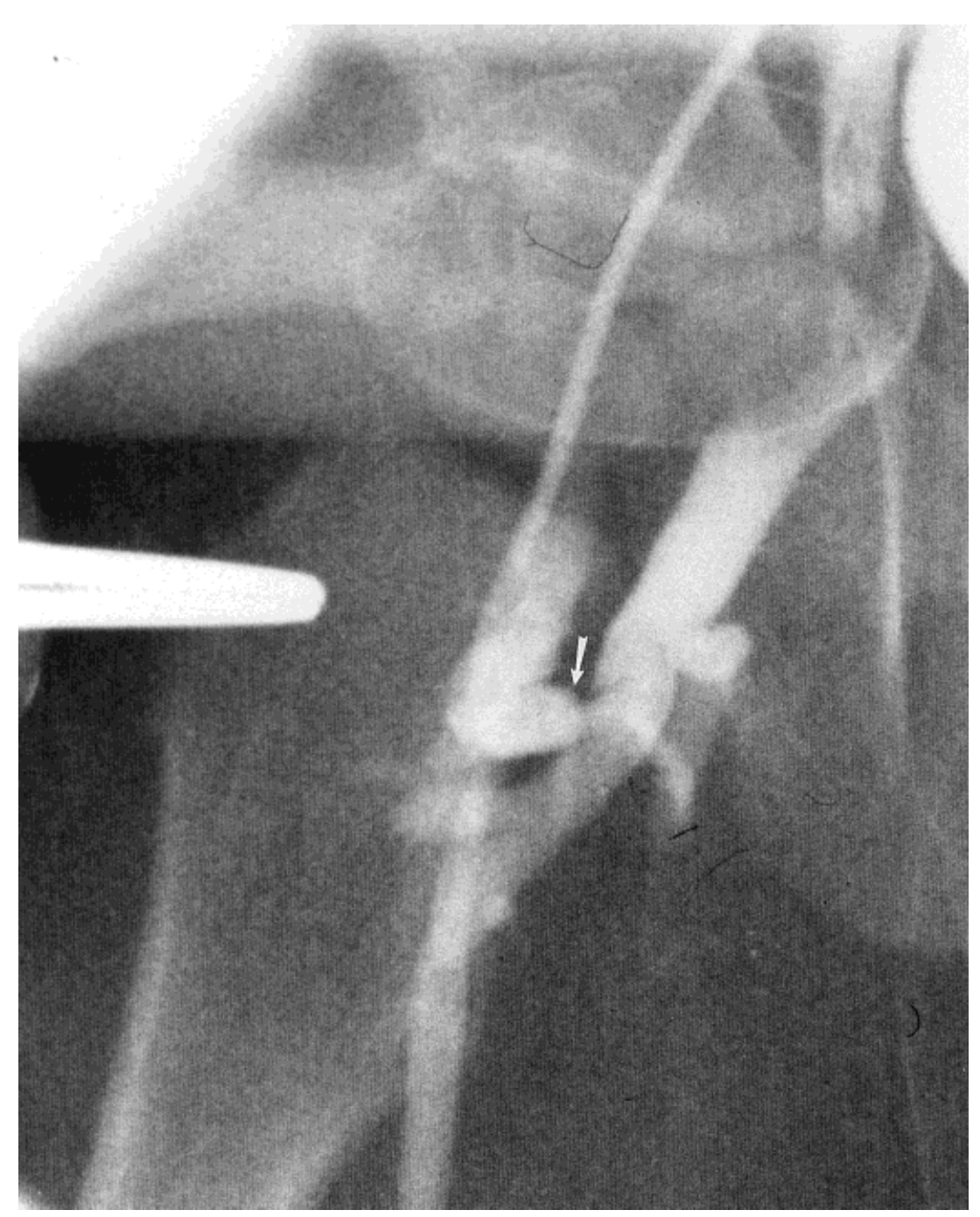

side, with gradual pulling back of the catheter across the fistula and subsequent release of the bulk of the coil on the arterial side. Subsequent angiography confirmed complete occlusion of the fistula (Fig. 2). The thrill and bruit over the right groin resolved after coil placement. Oxygen saturation in the inferior vena cava decreased from $77 \%$ to $55 \%$ after embolization, without change in arterial saturation. Therefore, the arteriovenous oxygen content difference in the lower segment tripled. No evidence of arterial or venous insufficiency of the right lower extremity was observed after catheterization or on follow-up.

\section{DISCUSSION}

Our patient had substantial volume overload of his single right ventricle as a consequence of shunting through the FAVF. Oxygen saturation data before and after occlusion of the FAVF suggest that the fistula shunt tripled his lowersegment blood flow, roughly doubling his ventricular output. Eccentric hypertrophy of the single ventricle is an important risk factor for the Fontan operation, and an important goal of the hemi-Fontan or bidirectional cavopulmonary anastomosis procedures is to reduce ventricular volume overload [3]. For this reason, we considered closure of the FAVF essential before completing the Fontan operation, and we delayed surgery for several months to allow involution of the eccentric hypertrophy. A lateral tunnel Fontan was completed 5 mo later, and the patient is doing well 10 mo after surgery.

Several alternative treatments for FAVF have been reported [4-6]. When FAVF is discovered soon after femoral catheterization, ultrasonography-guided compression or simple observation has been effective [7]. We did not favor these options, because we believed the 


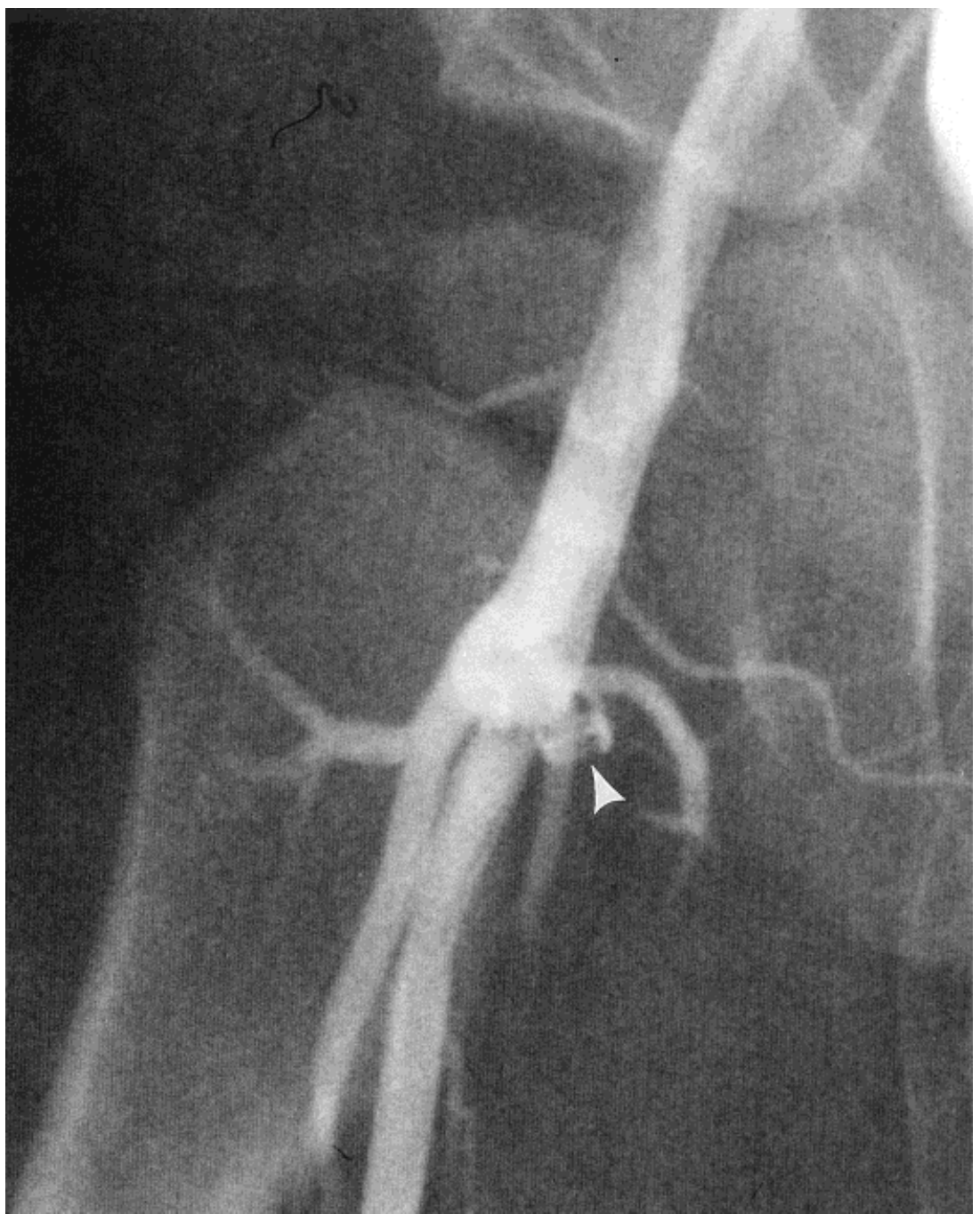

Fig. 2. After coil occlusion of the femoral arteriovenous fistula, angiography of the right femoral artery shows unobstructed arterial flow without residual fistula flow. Note the Gianturco coil (arrowhead) in the previous position of the fistula, with no impingement on the arterial lumen.
FAVF to have been present for a year. Covered stent implantation has been reported in adults [5], but this is highly impractical in a toddler and unlikely to preserve patency of the femoral vessels. Surgical repair of the FAVF was considered the only viable alternative to coil embolization in our patient.

Waigand et al. [6] reported coil implantation into 12 FAVF in adults, with complete occlusion in 11 and surgery required in one. They stressed the importance of selective angiography within the fistula and placement of coils within the fistula neck. Neither of these strategies was possible in our case, because of the small size and short fistula length of our patient. We were able to image the FAVF adequately in our patient by contrast injection into the femoral vein side of the fistula during external compression of the vein more proximally. Alternatively, the vein could be occluded temporarily using a balloontipped catheter.
It is worthwhile to note that FAVF is reported much less frequently in pediatric than in adult cardiac catheterization. Waigand et al. [6] estimated that FAVF and/or femoral pseudoaneurysm developed in $1.7 \%$ of their adult patients; we have observed one case of femoral pseudoaneurysm [2] and the present case of FAVF in our last 4,000 patients $(0.05 \%)$. A report from Toronto of complications in 5,000 pediatric cardiac catheterizations [8] found no cases of FAVF.

\section{CONCLUSION}

A high-flow FAVF in a small child was effectively and safely occluded using a Gianturco coil. Compression of the femoral vein above the fistula allows for clear angiographic documentation of the vessel, assisting coil selection and placement. Coil embolization of the fistulous 
connection has potential advantages over other treatment methods and should be considered in children with FAVF.

\section{REFERENCES}

1. Glaser RL, McKellar D, Scher K. Arteriovenous fistulas after cardiac catheterization. Arch Surg 1989;124:1313-1315.

2. Lloyd TR, Fedderly R, Mendelsohn AM, Sandhu SK, Beekman $\mathrm{RH}$. Transcatheter occlusion of patent ductus arteriosus with Gianturco coils. Circulation 1993;88:1412-1420.

3. Pridjian AK, Mendelson AM, Lupinetti FM, Beekman RH, Dick M, Serwer G, Bove EL. Usefulness of the bidirectional Glenn procedure as staged reconstruction for the functional single ventricle. Am J Cardiol 1993;71:959-962.

4. Litherland JC, Ashleigh RJ. Case report: transvenous embolization of a traumatic arteriovenous fistula. Clin Radiol 1996;51:886-889.
5. Marin ML, Veith FJ, Panetta TF, Cynamon J, Barone H, Schonholz C, Parodi JC. Percutaneous transfemoral insertion of a stented graft to repair a traumatic femoral arteriovenous fistula. J Vasc Surg 1993;18:299-302.

6. Waigand J, Uhlich F, Gross M, Thalhammer C, Dietz R. Percutaneous treatment of pseudoaneurysms and arteriovenous fistulas after invasive vascular procedures. Cathet Cardiovasc Intervent 1999;47:157-164.

7. Allen BT, Munn JS, Stevens SL, Sicare GA, Anderson CB, Droste ML, Ludbrook PA. Selective non-operative management of pseudoaneurysms and arteriovenous fistulae complicating femoral artery catheterization. J Cardiovasc Surg 1992;33:440 447.

8. Vitiello R. McCrindle BW. Nykanen D. Freedom RM. Benson LN. Complications associated with pediatric cardiac catheterization. J Am Coll Cardiol 1998;32:1433-1440. 